\title{
Analysis of Digital Human Resource Services of Sports Based on the Supply-demand Balance of Human Resources
}

\author{
Changshui Cui \\ Xi'an International University, Xi'an 710077 China
}

Keywords: sports human resources; supply-demand balance; digital human resource services.

\begin{abstract}
Human resources service is a task that coordinates enterprise human resource requirements and strategic management. At present, the focus of human resource management is scientifically predicting, analyzing and organizing human resources work to achieve a good ratio of human resources supply and demand, so as to comprehensively respond to changes in the development strategy of the enterprise. This paper first focused on the analysis of the management status quo of sports human resources and the prerequisites for achieving a balance between supply and demand of human resources. With knowing the relationship between the human resources management strategy of sports enterprises and the supply-demand balance of human resources, the author made corresponding analysis of the supply-demand balance of sports human resources, with the purpose to achieve better management of sports human resources and the actual development of enterprises.
\end{abstract}

\section{Foreword}

Human resource management (HRM) is to explore new possibilities in enterprise management and achieve standardized management of the enterprises' human cost and resources. With the rapid development of China's sports industry, it has gradually expanding demand for modern talents, which further highlights the great significance of the digital resource service for sports human resources. The achievement of a balance between supply and demand for human resources, to a large extent, means that the human capital and other operating capital of an enterprise can work in harmony and promote each other. At the same time, because HRM largely means the overall coordination and management of corporate capital, talents and goods, the imbalance between supply and demand of human resources will inevitably restrict the development of enterprises. To enhance analysis of the supply-demand balance of human resources in this realistic environment is easier to form targeted strategies to help enterprises achieve the overall development of management.

\section{Factors Affecting the Supply-Demand Balance of Human Resources in Enterprises}

The HRM in the sports industry is a project complex and huge. According to the relevant principles of economics, it can be clarified that the realization of supply-demand balance is often a dynamic change in both supply and demand, and the point of achieving supply-demand balance is also the one of optimal resource allocation. Therefore, rational economic men want to achieve a reasonable allocation of relevant resources in order to obtain greater benefits. The same is true for human resources, which also means that the factors affecting the supply-demand balance of human resources mainly come from two aspects, namely external supply and internal demand.

\subsection{Factors of External Supply}

The analysis of human resource needs is more centered on "things", and therefore the analysis of human resources supply must focus on "manpower". The status of the external labor market largely determines the recruitment process of enterprises. When the external labor market is tense, the number of external supplies will reduce, and the demand for human resources will have a certain degree of expansion. The decisive factors of external supply also include the season, industry, requirements of human resource, etc. In terms of seasonal characteristics, the supply of human resources in winter is less than that in spring and summer. As far as the industry is concerned, the 
supply of human resources for general industries is relatively abundant, while special industries (such as engineering technology, computers, etc.) show large differences in regional supply.

\subsection{Factors of Internal Demand}

The demand for human resources shows a certain degree of introversion, which mainly manifests as that the actual needs of enterprises drive the flow of relevant manpower in the human resource market. The internal needs of an enterprise are also very complex, generally greatly related with the enterprise's operating conditions, development stage, salary levels, and strategic goals, etc. In terms of the business conditions of the enterprise, an enterprise generally have greater human resource demand when it is with good performance, expanded products and increasing market investment; and at the other hand, the increased human resources will be of great significance to the business operation and product development. In addition, the demand of an enterprise for human resources is also quite different at different stages of development. This is because, the amount of tasks and actual needs of the enterprise for human resources are all different when it is at the different stages of business development, which in turn leads to changes in its demand for human resources. This change in demand mainly takes place during the growing stage and declining stage of the enterprise. In the growing stage of the enterprise, its business gradually expands and the business volume gradually increases. In addition, its organization structure becomes complicated and its demand for human resources is also increasing. In the declining stage of the enterprise, its business gradually reduces, and its organizational structure tends to be concise. During this period, the number of posts and staff required in this enterprise also decreases. Due to the change of the enterprise's life cycle, changes also take place in its organizational structure, business and its demand for human resources. At this time, the enterprise will adopt a series of adjustment strategies to regulate the supply and demand of human resources. Two conditions must be met to make supply and demand reach a balanced state. The first one is that the enterprise can accurately determine changes in its demand for human resources in real time. The other one is that the manpower adjustment strategy of the enterprise can guarantee its demand for human resources.

\section{Digital Human Resource Services of Sports Based on the Supply-Demand Balance of Human Resources}

\subsection{To Conduct Analysis of Enterprise Human Resources to Identify Effective Human Resource Requirements}

The composition of human resources in the sports industry is complex with large turnover. There are both technical and marketing talents in this industry. Different from other industries, the professional training of talents in the sports industry is insufficient and there are flaws in the targeting of human resources services. Therefore, when an enterprise has any supply-demand imbalance in human resources such as overstaffing, an effective method is to analyze the status quo of its human resources from various aspects, including the age structure, seniority structure, skills, work performance, etc. It is also necessary to analyze the flow of employees, including turnover of a certain post or specific department in the past month, three months or half year. In this way, relevant management personnel can understand the imbalances of the enterprise's human resources demand and its main requirements, so as to take appropriate measures to supplement the posts with frequent turnover, including increasing performance incentives and basic salary, standardizing working hours, limiting hours and days of overtime work and improving employee satisfaction with the enterprise.

In the actual management of employees, traditional HRM of sports often overlooks that the employees of an enterprise are a whole in a sense. The decentralized management method has a great impact on improving the overall efficiency of employees, but it is not conducive to the management of employees. Through the establishment of a sound performance management, the good combination of performance and flexible salary system can effectively motivate employees. Moreover, a unified performance assessment also excludes the influence of external factors such as seditious or black-box operations on the HRM, which enables employees of the enterprise to maximize their contribution value under the unified performance system, leading to the intensive 
effect of HRM. It is of great significance to the future development of the sports industry. This intensive effect cannot only be reflected in the degree of intensification of production efficiency, but also be embodied in the intensive degree of work attitude which promotes the jointly benign development of the corporate culture and economic interests.

\subsection{To Establish a Correct Management Concept of Human Resources Supply and Demand}

Enterprises not only need to obtain human resources, but also to develop and train human resources and then to meet the human resources management. It should be clarified that the sports industry refers to the collection of the same type of economic activities and the integration of similar economic sectors providing sports products for the society. Sports products include both tangible sports products and intangible sports services; the sports economic department not only includes market enterprises, but also covers various other organizations engaged in business activities, such as public institutions, social organizations and even individuals. To gain operating income and social benefits through the acquisition of human resource services, this huge industry needs to attach importance to the management of different types of talents to maintain a moderate surplus of human resources. This will allow the enterprise to operate normally and also avoid cost increase caused by excess human resources. To achieve this state of human resources, enterprises need to raise the management of human resources to the height of the operation, which requires these enterprises to put forward their own ideas for HRM and enrich the content of human resources.

To establish a comprehensive analysis mechanism for the human resources market, the relevant personnel of enterprises must constantly analyze the dynamic changes in the market behavior and the sports industry's demand for talents, timely control the changes in human resource requirements and better match the different characteristics of human resources supply, so as to give full play to the initiative and technicality of the human resources department. Sports enterprises need to lay stress on both the technical and non-technical aspects of HRM. Based the existing work system and management methods, enterprises should abandon the limitations of the work-centered administration and use people-oriented management methods to exert employees' subjective initiative and enhance their creativity.

\subsection{To Standardize the Employees Recruitment in the Sports Industry and Improve the Effectiveness of HRM}

The important link in improving recruitment planning is to achieving a fit with the business strategy of the sports industry. This is an objective plan for the comprehensive development and planning of the enterprise. It has been mentioned above that standardizing the employee recruitment can maximize the expansion of high-quality employees and make up for the deficiency in the shortage of personnel. Therefore, the following feasible suggestions are proposed for the recruitment:

1 To strengthen the internal coordination of the enterprise and attach importance to the development of the overall situation. Recruitment of sports enterprises can often reflect the complex composition of personnel and complicated management regulations. Therefore, in the current internationalized development, the sports industry must reform the previous recruitment management system and philosophy, strengthen the synergies among various departments within the enterprise, define the overall development as a strategic goal and eliminate desertions in thinking or behaviors.

2 To establish a digital service system of sports human resources. It is necessary to start with the demand and supply of human resources to analyze the dynamic relationship between the current situation of the talents and the actual demand in the sports industry, and establish a good digital human resources service system by using the supply-demand balance theory, big data and other information systems. At the same time, it is necessary to learn the advanced management experience of western companies (the recruiter allocation, management process, rules of regulations, etc.), so as to correct the trajectory of the enterprise's development to achieve higher goals and accelerate the effectiveness of strategic management.

In addition, the recruitment planning of modern enterprises should first be based on human resource planning. In the recruitment process, a modern digital service system of human resources should be adopted to recruit talents for different posts of the sports industry, such as technical talents, marketing talents, management talents, and so on. Enterprises are supposed to understand the 
timeframe, number as well as the type and quality of talents to be recruited through the digital service system. Recruitment planning should combine internal and external factors. Internal factors should include recruitment posts, recruitment plans, recruitment time and cycle, job vacancy, target number of employees to be recruited, etc. External factors cover suitable recruitment channels, the design and grooming of the recruitment process, the evaluation and forecast of the recruitment market, the forecast of the costs incurred in the recruitment, the evaluation of the recruitment effect, etc. The contents above can be applied in the development of a scientific and reasonable recruitment plan, so as to satisfy the human resource demand and promote the realization of supply-demand balance for human resources of sports enterprises. Enterprises should incorporate their own development strategies and human resource recruitment plans into their recruitment models, and their human resource planning should be based on the strategic planning and development goals of their own.

\section{Conclusion}

To sum up, the supply-demand balance of human resources in the sports industry involves the dynamic development of supply and demand in the human resource market, and it is related to the enterprises' business situation and the possibility of continuous development and progress. Good HRM means that the enterprise has achieved a better allocation of resources and can balance the relationship between costs and benefits well. At the same time, it also means a rational structure of human resources which is of great significance to the long-term management of the enterprise. In addition to comprehensive analysis of the performance of the supply-demand balance of sports human resources, the paper also analyzed the construction of modern digital sports human resources services based on the supply-demand balance theory of human resources. After clarifying the actual needs of the development of the sports industry for improving the efficiency of human resource services, corresponding suggestions and countermeasures were proposed to build digital human resource services from the planning, management, recruitment and other aspects of human resources, which will be of great significance to promote the human resource services for sports in the real environment.

\section{Acknowledgements}

Fund project: Scientific research project of Shaanxi provincial education department in 2017(17JK1092)

Project Name: the path of human resources supply in Shaanxi sports service industry.

\section{References}

[1]. Zhang Tao. Analysis of Supply and Demand Balance of Corporate Human Resources [J]. Northern Economy \& Trade, 2015(02):157+161.

[2]. Zuo Yinjie. Research on the Human Resource Planning of the Z Company Based on the Enterprise Core Strategy [D]. Shanghai International Studies University, 2014.

[3]. Tian Hua. Research on the Development of Sports Human Resources in Common Institutions of Higher Learning in Zhangjiakou City [D]. Hebei Normal University, 2017.

[4]. Luo Ying. Analysis of Interactive Development of College Sports and Community Sports in Langfang City [D]. Hebei Normal University, 2017.

[5]. Lu Junbo. Research on Strategy of Improving Human Resources Management Innovation and Ability [J]. Macroeconomic Management, 2017(S1): 140-141. 